\title{
A COMPARISON BETWEEN SURGICAL TECHNIQUES AND RESULTS OF ENDOSCOPIC DACRYOCYSTORHINOSTOMY VERSUS EXTERNAL DACRYOCYSTORHINOSTOMY
}

\author{
Kapil Jain ${ }^{1}$, Shakti Rajguru²
}

${ }_{1}^{1}$ Senior Resident, Department of ENT, Government Medical College, Barmer, Rajasthan, India.

${ }^{2}$ Senior Resident, Department of Ophthalmology, Government Medical College, Barmer, Rajasthan, India.

\begin{abstract}
BACKGROUND
ABSTRACT

Dacryocystorhinostomy (DCR) has been touted as the standard procedure for acquired Nasolacrimal Duct Obstruction (NLDO). It can be performed through a cutaneous incision, traditionally referred to as external DCR or via a transnasal approach under either direct visualisation or endoscopic guidance. In both approaches, the lacrimal sac mucosa is connected to the nasal mucosa above the level of the mechanical obstruction at the nasolacrimal duct. Toti's technique of external dacryocystorhinostomy (DCR) has been the treatment of choice for epiphora due to nasolacrimal duct obstruction, since 1904. With the introduction of rigid nasal endoscopes in the 1970s and the advent of endoscopic sinus surgery using powered instruments, microdebrider intranasal endoscopic dacryocystorhinostomy has been done by many otorhinolaryngologists.
\end{abstract}

\section{MATERIALS AND METHODS}

This study compares the stepwise procedure and outcome of external dacryocystorhinostomy with endoscopic endonasal dacryocystorhinostomy. 50 patients who were diagnosed with nasolacrimal duct obstruction or chronic dacryocystitis were included in the study. They were randomised into two groups. Group I included 25 patients who underwent external dacryocystorhinostomy and Group II included the rest of the 25 patients who underwent endoscopic endonasal dacryocystorhinostomy.

\section{RESULTS}

Although, both the procedures had a success rate of above 90\%, endoscopic DCR was helpful in avoiding a scar on the face and injury to the neighbouring structures like the medial palpebral ligament and the angular facial vessels. The surgical duration for endoscopic DCR was short as compared to that of the external approach.

\section{CONCLUSION}

Our study concludes that endoscopic DCR is as good as external DCR for the treatment of nasolacrimal duct obstruction and chronic dacryocystitis.

\section{KEY WORDS}

Endoscopic Dacryocystorhinostomy, External Dacryocystorhinostomy, Lacrimal Sac.

HOW TO CITE THIS ARTICLE: Jain K, Rajguru S. A comparison between surgical techniques and results of endoscopic dacryocystorhinostomy versus external dacryocystorhinostomy. J. Evolution Med. Dent. Sci. 2018;7(38):4196-4200, DOI: $10.14260 /$ jemds/2018/938

\section{BACKGROUND}

Chronic dacryocystitis is defined as the chronic inflammation of the lacrimal sac due to stricture of the nasolacrimal duct secondary to chronic inflammation, which is usually nasal in origin. The essential symptom is epiphora, which is aggravated by conditions such as exposure to wind. There may be swelling at the site of the sac (mucocele) and the neighbouring parts of the conjunctiva are frequently inflamed. On applying pressure over the sac, mucopus or sometimes frank pus regurgitates through the puncta. The bacteriological study of the fluid demonstrates the presence of a number of bacteria, both aerobic and anaerobic. The diagnostic procedures include lacrimal probing, lacrimal irrigation, dacryocystography, the Jones dye test, the

'Financial or Other Competing Interest': None.

Submission 27-01-2018, Peer Review 05-09-2018,

Acceptance 11-09-2018, Published 17-09-2018.

Corresponding Author:

Dr. Kapil Jain

Department of ENT,

Government Medical College,

Barmer-344001, Rajasthan, India.

E-mail: kapilmjain@gmail.com

DOI: $10.14260 /$ jemds $/ 2018 / 938$

fluorescein test and radionuclide cystography. Appropriate clinical and radiographical testing when indicated will aid in the diagnosis of dacryocystitis. For over a century, the gold standard of treatment for epiphora due to nasolacrimal duct obstruction has been dacryocystorhinostomy. It was Toti, who in 1904, reported this procedure for external dacryocystorhinostomy. He made a hole in the lacrimal sac and another hole in the nose and approximated the two with a tight pressure bandage. This operation has got refined over the years into the present day external dacryocystorhinostomy. Since the time of Toti, the only major advance in the technique has been the use of a silastic tubing. Endonasal dacryocystorhinostomy procedures were first described in 1893 by Caldwell, in which a portion of the inferior turbinate was removed, and the nasolacrimal duct was followed till the lacrimal sac. ${ }^{1}$ With the advent of rigid nasal endoscopes in the 1970s, the intranasal endoscopic approach to the lacrimal sac was feasible. A cadaveric study demonstrating endoscopic intranasal dacryocystorhinostomy was reported by Rice in 1988, followed by a review of 4 patients in $1990.2^{2}$ The first clinical study on endoscopic intranasal dacryocystorhinostomy was published by McDonagh and Meiring in 1989.3 Many variations of 
endoscopic dacryocystorhinostomy with little modifications like the use of stents, Laser, microdebrider and Mitomycin-C have been described in the last decade with equally good results. Although, Toti's operation of external dacryocystorhinostomy has in good hands a success rate of about $90 \%$, endoscopic dacryocystorhinostomy is gaining popularity as there is no facial scar and no disruption of the medial palpebral ligament or the angular facial vessels. This study compares the stepwise procedure and outcome of external dacryocystorhinostomy with that of endoscopic endonasal dacryocystorhinostomy. It is mostly done by endoscopic way by otorhinolaryngologist and by external approach by ophthalmologist. ${ }^{4,5}$

\section{MATERIALS AND METHODS}

We performed a non-randomised controlled trial study of 50 patients with diagnosis of nasolacrimal duct obstruction admitted in our hospital from October 2016 to October 2017. Preoperatively, a detailed ophthalmic and ENT examination was carried out to rule out any coexisting pathology. Preoperative investigations included a complete haemogram, blood sugar, bleeding and clotting time etc. Selection of type of operation was left to the patient's choice. All patients had preoperative counselling and both the procedures were explained in detail with their advantage and disadvantage. A total of 25 patients were enrolled by simple randomisation in external DCR group and 25 patients in the endoscopic DCR group. Study by convenient allocation technique since the duration of the study was few months. The patients were selected by convenience allocation technique. The sample size estimation was also done at conveniences.

\section{Inclusion Criteria}

1. All symptomatic cases of epiphora, which were diagnosed for primary acquired nasolacrimal duct obstruction or chronic dacryocystitis.

2. Those who were willing to undergo surgery.

\section{Exclusion Criteria}

1. Cases with canalicular and punctal obstruction.

2. Cases with ectropion or entropion.

3. Cases with noticeable lower lid laxity.

4. Cases with nasal polyposis.

5. Cases with severe nasal deviation.

\section{Operative Procedure}

Position: Patient lying supine with head up using head ring or a pillow under the head.

\section{External Dacryocystorhinostomy}

1. The nose is packed with nasal wig soaked in solution of $15 \mathrm{~mL} \mathrm{4 \%}$ xylocaine with 6 drops of xylometazoline nasal drops.

2. Premedication of $1 \mathrm{~mL}$ pentazocine, $1 \mathrm{~mL}$ phenergan and $1 \mathrm{~mL}$ atropine given intramuscular 30 minutes before the surgery.

3. Local and topical anaesthesia.

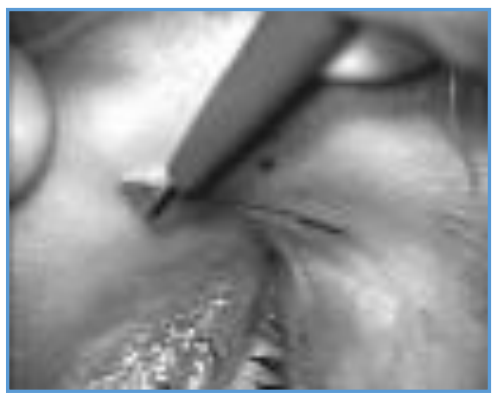

Skin Incision at Medial Canthus

4. Skin Incision: Curvilinear or straight $10 \mathrm{~mm}$ long $8 \mathrm{~mm}$ medial to inner canthus.

5. MPL exposed by blunt dissection and then cut to expose anterior lacrimal crest and periosteum elevated.

6. Lacrimal sac exposed and dissected away from lacrimal fossa.

7. With the use of Kerrison bone punch bony ostium of size $15 \mathrm{~mm} \times 10 \mathrm{~mm}$ created.

8. Exposure of thin pinkish white nasal mucosa done.

9. Flap Formation: Sac flap - using Bowman's probe as a guide, " $\mathrm{H}$ " shaped incision is made. Nasal mucosal flap$\mathrm{H}$-shaped incision made along bony ostium.

10. Flap anastomosis using 6-0 Vicryl - Posterior flap of sac and nasal mucosa is sutured, then anterior flap of nasal mucosa and sac are sutured.

11. Wound closure of medial palpebral ligament and orbicularis oculi with 6-0 Vicryl and skin with 6-0 silk.

12. Nasal packing done.

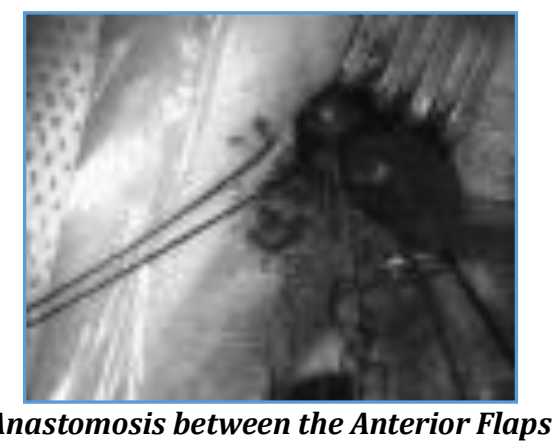

\section{Endoscopic Dacryocystorhinostomy}

1. The nose is packed with nasal wig soaked in solution of $15 \mathrm{~mL} \mathrm{4 \%} \mathrm{xylocaine} \mathrm{with} 6$ drops of xylometazoline nasal drops.

2. Premedication of $1 \mathrm{~mL}$ pentazocine, $1 \mathrm{~mL}$ Phenergan and $1 \mathrm{~mL}$ atropine given intramuscular 30 minutes before the surgery.

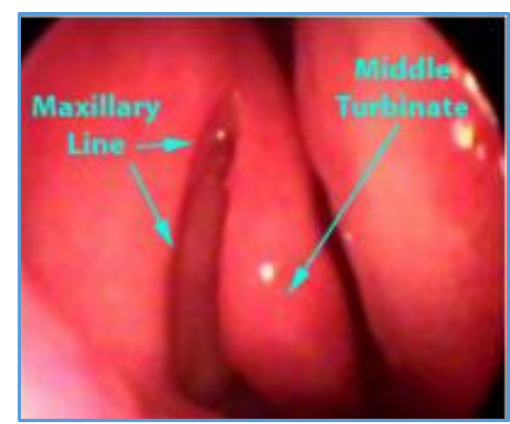


3. Nasal endoscopy is performed with a 30-degree rigid nasal endoscope.

4. Identify the middle turbinate, trace its anterior arch laterally as premaxillary line.

5. The area in front of maxillary line is the premaxillary line or lacrimal sac area.

6. The sac is covered by the lacrimal bone, which is to be removed during the surgery.

7. Inject $2 \%$ xylocaine with adrenaline $(1: 200000)$ to the lacrimal sac area, middle turbinate and some part of nasal septum (as it is sensitive to touch).

8. Adrenaline should not be used if contraindicated and xylocaine sensitivity should be checked before the procedure.

9. Remove the mucosa with a sickle knife and with microdebrider and expose the lacrimal bone area completely.

10. Perforate the lacrimal bone with Kerrison bone punch. Once small opening is made, press the lacrimal sac from outside. The movement of medial wall of sac in the endoscopic view will confirm the lacrimal sac.

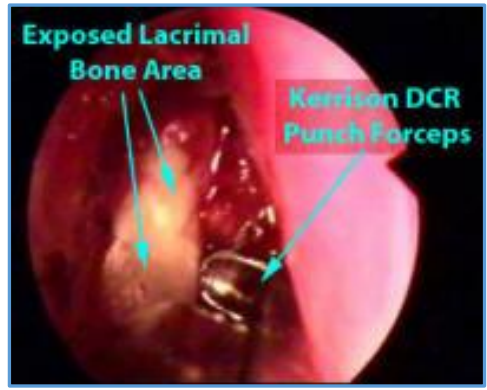

11. Enlarge the newly created stoma as big as possible.

12. The lacrimal punctum is cannulated, and lacrimal sac is filled with saline.

13. Create a vertical incision in lacrimal sac using sickle knife or scalpel knife number 12 .

14. Nasal probe is passed into the incision and dilatation done.

15. Enlarge the newly created stoma using microdebrider.

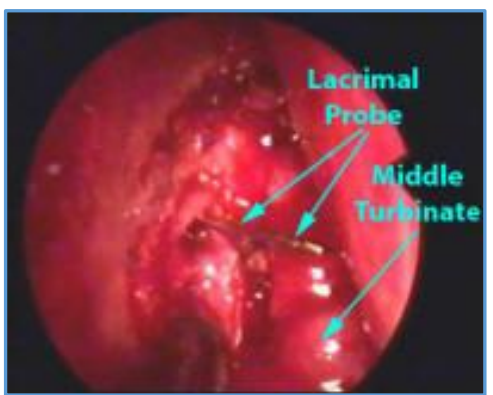

16. Pass the lacrimal bone from lower punctum of eye. Negotiate it to come out from newly created inside the nose to break any adhesion at opening of nasolacrimal duct near the sac.

17. Do sac syringing. Free flow of saline indicates successful surgery.

18. Light nasal packing.

19. Patient is discharged in the evening after pack removal.

20. One-week course of oral antibiotic and antibiotic eye drop.
21. Sac syringing at regular intervals for first two months.

\section{Outcome Measures}

Surgery failure was defined as: (1) No marked improvement in tearing or any episode of post-operative dacryocystitis; (2) Inability to irrigate the lacrimal system postoperatively; and (3) Postoperative nasal endoscopy with scarring in intranasal osteotomy or no visualisation of fluorescein dye. Postoperative nasal endoscopy was performed in all cases.

\section{Statistical Analysis}

All observations were tabulated and analysed using independent student's ' $\mathrm{t}$ ' test and Chi-square test in Statistical Package for Social Sciences (SPSS) software version 22. Statistically significant difference in findings was considered when p-value was $<0.05$.

\section{RESULTS}

In this study, total 50 eyes of 49 patients were included. 25 out of total 50 eyes had undergone endoscopic DCR and 25 had external DCR. All 25 in endoscopic DCR group underwent powered endoscopic surgery using microdebrider.

Most of the patients in the endoscopic group were in 2035 years, whereas in the external DCR group the majority of cases were in 35 - 50 years' age group. The mean age in endoscopic DCR group was 31 years. The mean age group in external DCR was much higher, i.e. 45 years. The age distribution between the groups was statistically significant. In both groups of patients, female preponderance was seen Males constitute 18 cases (36\%), while female constitute 32 (64\%) cases.

Overall, the eyes operated in different age groups showed preponderance of right eye. The percentage of right eye involvement was $68 \%$ and left eye involvement was $32 \%$. This result was not statistically significant with respect to the side of the eyes between the groups.

The commonest indication for DCR was epiphora. Thirty one eyes (62\%) out of 50 presented with symptoms of lacrimation, 14 eyes (28\%) had mucocele at the time of presentation along with epiphora and five patients were diagnosed as having acute dacryocystitis preoperatively on the basis of symptoms and treated medically before operation.

The average duration for endoscopic DCR surgery was 46 minutes and 86 minutes for external DCR ( $p<0.001)$. The minimum time taken for endoscopic surgery in all groups was 30 minutes and maximum was 60 minutes. The minimum and maximum time for external DCR was 60 minutes and 100 minutes, respectively. The difference in duration of surgery between the groups was statistically significant.

Complication rate was low in both types of surgery. Complication included excessive intraoperative bleeding, which was seen in 7 and 5 cases of external and endoscopic DCR respectively. One patient had lacrimal sac flap loss during separation of sac from lacrimal fossa and loss of nasal mucosa during cutting occurred in two patients in external DCR. There were no such complications noted in endoscopic DCR surgery. All these complications were managed conservatively.

The average follow-up period was 6 months. In endoscopic DCR group, out of 23 cases 25 cases (92\%) demonstrated primary surgical success which is defined as 
decreased or absent epiphora and adequately patent lacrimal system in the $1^{\text {st }}$ month of follow-up period. Twenty-four (98\%) out of 25 cases had patent lacrimal passage and one presented with functional block after 1 month in external DCR group. Failure rate in endoscopic and conventional DCR was $8 \%$ and $2 \%$, respectively.

\section{DISCUSSION}

External DCR surgery at the turn of the century was regarded as the gold standard in treatment for nasolacrimal duct obstruction. ${ }^{6}$ This procedure has got advantages of direct visualisation of the anatomical structures surrounding the lacrimal sac compared to endoscopic DCR. ${ }^{7}$ Disadvantages of this procedure includes cutaneous scar and the potential for injury to medial canthal structures, cerebrospinal fluid rhinorrhoea and functional interference with the physiological action of lacrimal pump. ${ }^{8}$

However, endoscopic DCR is getting popularity among patients due to equal promising results and especially due to lack of external scar. ${ }^{7}$ Endoscopic DCR allows direct inspection of lacrimal sac for underlying pathology. Assessment of failure can also be viewed endoscopically, so mistakes can be corrected immediately. Again, it can be converted to external DCR in difficult cases or those with lacrimal sac tumours. ${ }^{9}$

Our study was a prospective, non-randomised study done on 50 eyes of 49 patients presented with epiphora or chronic dacryocystitis. In our study, female-to-male ratio was 1.77: 1. This shows that the nasolacrimal sac and duct obstruction is more common in females than males. This result corroborates with previous studies. ${ }^{10,11,12}$

The mean age of the patients who underwent endoscopic DCR was 31 years compared to external DCR group, which was 45 years. This indicates that acquired nasolacrimal duct obstruction is more common in middle age group. There is a declining trend towards both extremes of age. This may be due to the fact that amount of lacrimal secretion is less in extremes of ages. Similar data was found by many previous workers.7,12,13,14 However, few workers found that the mean age group is slightly more than our findings.6,11,15

In present study, $68 \%$ of the cases presented with disease on right side. This does not correlate with previous studies.12,16 However, Nichlani et al found right eye involvement more than left eye, which corroborates with our study. ${ }^{17}$ In our study, the exact cause of right eye involvement in dacryocystitis was not known.

In our study, epiphora was the commonest presenting symptom as found in similar studies.6,17,18

In a study in Bangladesh, the duration of surgery in endoscopic DCR was $59.7 \pm 8.8$ minutes which was significantly higher than for external DCR group which was $54.3 \pm 5.6$ minutes. ${ }^{9}$ Muscatello et al showed that mean time for endonasal endoscopic DCR was 30 minutes, range 15-110 minutes and time progressively decreased with increasing surgical experience. ${ }^{19}$ Hartikainen et al concluded that average duration for endoscopic DCR was 38 minutes and 78 minutes for external DCR. ${ }^{20}$ We found that average time required for endoscopic DCR was 46 minutes as compared to external DCR was 86 minutes. In our study, we found that surgical times are closely related to the surgical experience of the surgeon and intraoperative bleeding.

\begin{tabular}{|c|c|c|c|c|c|}
\hline \multirow{2}{*}{$\begin{array}{c}\text { S1. } \\
\text { No. }\end{array}$} & \multirow{2}{*}{$\begin{array}{c}\text { Intraoperative } \\
\text { Complication }\end{array}$} & \multicolumn{2}{|c|}{$\begin{array}{c}\text { Endoscopic } \\
\text { DCR }\end{array}$} & \multicolumn{2}{|c|}{$\begin{array}{c}\text { External } \\
\text { DCR }\end{array}$} \\
\cline { 3 - 6 } & No. & \% & No. & $\%$ \\
\hline 1 & Bleeding & 5 & 20 & 7 & 28 \\
\hline 2 & Lacrimal sac flap loss & 0 & 0 & 1 & 4 \\
\hline 3 & $\begin{array}{c}\text { Loss of nasal mucosa during } \\
\text { bone removal }\end{array}$ & 0 & 0 & 2 & 8 \\
\hline 4 & $\begin{array}{c}\text { Orbital injury and CSF } \\
\text { rhinorrhoea }\end{array}$ & 0 & 0 & 0 & \\
\hline
\end{tabular}

Intraoperative Complication Endoscopic DCR External DCR

P-value was $<0.05$.

The average follow-up period was 6 months in our study. The primary surgical success rate in endoscopic DCR group was $92 \%$ and $98 \%$ in external DCR group after 6 months of follow-up period.

The success rate for endoscopic DCR appears to be comparable to the "gold standard" external approach with success rate ranging from $78 \%$ to $97 \%{ }^{21,22}$ Our success rate in both groups is comparable to various studies. Khan et al showed that success rate was $73.3 \%$ with endoscopic approach and $80 \%$ with external approach. ${ }^{9}$ Karim et al has found similar success rate in both approaches (endoscopic DCR $82.4 \%$ versus external DCR was $81.6 \%$; $p=0.895) .{ }^{6}$ In the study, Gupta et al found that success rate of endonasal DCR was $90 \%$ after a single procedure and $95 \%$ after revision procedure which was equal to external approach, which is comparable to our study. ${ }^{13}$

Our study had some limitations. Our study was a hospitalbased study, which caused some bias in patient selection. The study period is also short. As younger patients preferred endoscopic DCR, there is a difference in age group between the patients of endoscopic and external DCR. This may affect the surgical outcome which is a limitation of our study. Again as the endoscopic and external DCR procedures were performed by different surgeons, which may also affect the surgical outcome. This is also a limitation of our study.

\begin{tabular}{|c|c|c|}
\hline & Endoscopic DCR & External DCR \\
\hline Scar & No & Yes \\
\hline Bleeding & Less & More \\
\hline Duration & Less & More \\
\hline $\begin{array}{c}\text { Risk of injury to medial } \\
\text { canthus structure }\end{array}$ & Less & More \\
\hline Postoperative morbidity & No & Yes \\
\hline \multicolumn{2}{|c|}{ Comparison with Endoscopic DCR and External DCR } \\
\hline
\end{tabular}

\section{Limitation of the Study}

Due to short duration of study, convenience allocation technique was followed. The sampling size was also calculated by convenience. The results of the study cannot be generalised due to the potential bias resulting from the allocation technique and sample size estimation.

\section{CONCLUSION}

It can be concluded that endoscopic DCR is as good as external DCR for the treatment of primary nasolacrimal duct obstruction and chronic dacryocystitis. The surgical duration for endoscopic DCR is short as compared to that of the external approach. Endoscopic DCR avoids a scar on the face and injury to the neighbouring structures like the medial palpebral ligament and the angular facial vessels. With the 
widespread use of nasal endoscopes, this surgery is gaining popularity over external dacryocystorhinostomy.

\section{REFERENCES}

[1] Susan MH. The history of lacrimal surgery. Adv Opthal Plastic Reconstruct Surg 1986;5:139-68.

[2] Rice DH. Endoscopic intranasal dacryocystorhinosomy: results in 4 patients. Arch of Otolaryngol Head and Neck Surg 1990;116:1061.

[3] McDonough M, Meiring JH. Endoscopic transnasal dacryocystorhinostomy. Journal of Laryngology and Otology 1989;103(6):585-7.

[4] Sinha V, Chhaya V, Mehta K, et al. The surgical technique of endoscopic dacrocystorhinostomy. Is this surgery going from the hands of ophthalmologists? World Article in Ear, Nose and Throat 2009. (Manuscript \& Video) http://www.waent.org/archives/2009/vol2-1/v2-109.html

[5] Deshpande S, Agashe A, Loomba A, et al. Step by step dacryocystorhinostomy for beginners: an expert's view. J Clin Ophthalmol Res 2014;2(3):161-5.

[6] Karim R, Ghabrial R, Lynch TF, et al. A comparison of external and endoscopic endonasal dacryocystorhinostomy for acquired nasolacrimal duct obstruction. Clin Ophthalmol 2011;5:979-89.

[7] Khan MK, Hossain MA, Hossain MJ, et al. Comparative study of external and endoscopic endonasal dacryocystorhinostomy for the treatment of chronic dacryocystitis. JAFMC Bangladesh 2011;7(2):15-7.

[8] Shun-Shin GA, Thurairajan G. External dacryocystorhinostomy-an end of an era? $\mathrm{Br}$ J Ophthalmol 1997;81(9):716-7.

[9] Zhou W, Zhou M, Li Z, et al. Endoscopic intranasal dacryocystorhinostomy in forty-five patients. Chin Med J (Engl) 1996;109(10):747-8.

[10] Hurwitz JJ, Rutherford S. Computerized survey of lacrimal surgery patients. Ophthalmology 1986;93(1):14-9.

[11] Tan NC, Rajapaksa SP, Gaynor J, et al. Mechanical endonasal dacryocystorhinostomy - a reproducible technique. Rhinology 2009;47(3):310-5.
[12] Moras K, Bhat M, Shreyas CS, et al. External dacryocystorhinostomy versus endoscopic dacryocystorhinostomy: a comparison. J Clin Diagn Res 2011;5(2):182-6.

[13] Gupta S, Goyal R, Thakur AS, et al. Conventional dacryocystorhinostomy versus endonasal dacryocystorhinostomy - a comparative study. Peoples J Sci Res 2008;1:1-4.

[14] Küpper DS, Demarco RC, Resend R, et al. Endoscopic nasal dacryocystorhinostomy: Results and advantages over the external approach. Braz J Otorhinolaryngol 2005;71(3):356-60.

[15] Simon BGJ, Joseph J, Lee S, et al. External versus endoscopic dacryocystorhinostomy for acquired nasolacrimal duct obstruction in a tertiary referral center. Ophthalmology 2005;112(8):1463-8.

[16] Vishwakarma R, Singh N, Ghosh R. A study of 272 cases of endoscopic dacryocystorhinostomy. Indian J Otolaryngol Head Neck Surg 2004;56(4):259-61.

[17] Nichlani SS, Jagade MV, Ganeshan A. A comparative study between endoscopic and external approach dacryocystorhinostomy. Bombay Hosp J 2010;52:18996.

[18] Aslam S, Awan AH, Tayyab M. Endoscopic dacryocystorhinostomy: a Pakistani experience. Pak J Ophthalmol 2010;26:2-6.

[19] Muscatello L, Giudice M, Spriano G, et al. Endoscopic dacryocystorhinostomy: personal experience. Acta Otorhinolaryngol Ital 2005;25(4):209-13.

[20] Hartikainen J, Antila J, Varpula M, et al. Prospective randomized comparison of endonasal endoscopic dacryocystorhinostomy and external dacryocystorhinostomy. Laryngoscope 1998;108(12):1861-6.

[21] Smith W, Merkonidis C, Draper M, et al. Endoscopic dacryocystorhinostomy in warfarinized patients. Am J Otolaryngol 2006;27(5):327-9.

[22] Jin HR, Yeon JY, Choi MY. Endoscopic dacryocystorhinostomy: creation of a large marsupialized lacrimal sac. J Korean Med Sci 2006;21 (4):719-23. 